\title{
Application of Nanocomposites Based on Graphene and Metal Materials in Measurement of Nitrate/Nitrite in Food Samples
}

\author{
Arezou Akbari ${ }^{1}$ (D), Baharak Divband ${ }^{2,3}$, *, Parvin Dehghan 4, *iD , Amir Hossein Moradi ${ }^{1(D)}$ \\ 1 Student research committee, Faculty of Nutrition and Food Science, Tabriz University of Medical Sciences, Tabriz, Iran, \\ arezoakbari93@gmail.com (A.A.); amirmoradi431@gmail.com (A.H.M.); \\ 2 Dental and Periodontal Research Center, Tabriz University of Medical Sciences, Tabriz. Iran; divband@tabrizu.ac.ir \\ (B.D.); \\ 3 Inorganic Chemistry Department, Faculty of Chemistry, University of Tabriz, Iran, divband@ tabrizu.ac.ir (B.D.); \\ 4 Nutrition Research Center, Faculty of Nutrition and Food Science, Tabriz University of Medical Sciences, Tabriz, Iran; \\ Dehghan.nut@gmail.com (P.D.); \\ * Correspondence: divband@tabrizu.ac.ir(B.D.); Dehghan.nut@gmail.com (P.D);
}

Scopus Author ID 13612795900

Received: 10.12.2020; Revised: 16.01.2021; Accepted: 20.01.2021; Published: 31.01.2021

\begin{abstract}
Nitrite $\left(\mathrm{NO}_{2}{ }^{-}\right)$has been broadly applied in industrial and agricultural products; it is often found in various foods, water, environmental systems, and biological samples, though $\mathrm{NO}_{2}{ }^{-}$is a toxic inorganic contaminant that is hazardous to the health of humans and other organisms. In recent years several approaches have been recommended for detecting and monitoring $\mathrm{NO}_{2}{ }^{-}$that the electrochemical method is of very attention, among them, due to its easy miniaturization, cost-effective, rapidness, straightforward operation. Graphene nanocomposites have a considerable synergistic electrocatalytic effect toward the nitrite redox, magnifying the electrochemical response signals and improving the sensitivity, selectivity, and feasibility of the nitrite detection in various real samples. In this article, we report the recent developments in electrochemical sensors based on graphene/metal nanocomposites for the measurement of nitrate/nitrite in the food samples and identifying performances, including limit of detection (LOD), detection ranges, $\mathrm{pH}$, sensitivity, stability, and technology used were determined.
\end{abstract}

Keywords: electrochemical; graphene; metal; nanocomposite; nitrite; nitrate; food sample.

(C) 2021 by the authors. This article is an open-access article distributed under the terms and conditions of the Creative Commons Attribution (CC BY) license (https://creativecommons.org/licenses/by/4.0/).

\section{Introduction}

Nitrate $\left(\mathrm{NO}_{3}^{-}\right)$and nitrite $\left(\mathrm{NO}_{2}^{-}\right)$as inorganic compounds are found in natural and processed foods. These compounds are present in vegetables, specifically green leafy vegetables, such as spinach and lettuce, cabbage, red beet-root, radish, and drinking water, which contributes about $80 \%-95 \%$ of dietary $\mathrm{NO}_{3}$ intake; however, processed food and animal food products are commonly major sources for dietary $\mathrm{NO}_{2}{ }^{-}$intakes [1]. Oral commensal bacteria under the tongue or in the stomach are known to be responsible for changing dietary $\mathrm{NO}_{3}{ }^{-}$to $\mathrm{NO}_{2}^{-}$. Historically, there are several pieces of evidence showing that $\mathrm{NO}_{2}{ }^{-}$intake at high concentrations can be a serious threat for health due to its possible endogenous conversion to nitrosamines and increase in several severe and chronic toxicities such as thyroid disorders, methemoglobinemia, infant central nervous system defect, spontaneous abortion, and gastrointestinal cancers [2]. The methemoglobin leads to blue baby syndrome via decreasing oxygen transferring capacity, and nitrosamine is a factor for carcinogenicity. In return, one of 
the recent researches showed that restricted dietary $\mathrm{NO}_{2}^{-}$may stimulate numerous favorable effects, particularly on the cardiovascular system and metabolic pathways [3]. Thus, many countries have established strict roles on nitrite dosage. It was reported that the maximum contamination level for $\mathrm{NO}_{2}^{-}$in drinking water (WHO, USEPA) is $1.0 \mathrm{mg} / \mathrm{l}$. Also, WHO has determined acceptable daily intake (ADI) levels of nitrite $(0.07 \mathrm{mg}$ nitrate/ $\mathrm{kg}$ body weight per day) and nitrate (3.7 mg nitrate/ $\mathrm{kg} /$ day) largely based on drinking water standards [4]. It was estimated that in Iran, the mean dietary intake of $\mathrm{NO}_{3}^{-}$and $\mathrm{NO}_{2}^{-}$from different food groups and drinking water is $505 \pm 160$ and $7.7 \pm 2.2 \mathrm{mg} / \mathrm{d}$, respectively [1]. Concerning $\mathrm{NO}_{2}{ }^{-}$ importance in health, accurate estimation of $\mathrm{NO}_{2}{ }^{-}$content in food source seems to be a challenging issue and an important barrier for food and nutrition sciences because there is a close relationship between $\mathrm{NO}_{2}{ }^{-}$content and food safety. Over the past decade, the various process is proposed for the efficient analysis of nitrite, including ion-chromatography [5], spectrophotometric [6], chemiluminescence [7], capillary electrophoresis [8], and electrochemical method [9]. Most of the mentioned techniques require technical personnel and costly equipment besides being time-consuming. However, the electrochemical method is affordable, simple, and trustable, with high sensitivity, good selectivity, and rapid response. Therefore, it is known as an alternative method with high performance for controlling and strict testing of $\mathrm{NO}_{2}{ }^{-}$in foods. In electrochemical methods, the electrocatalytic oxidation of nitrite on the electrode surface occurs by factors such as platinum $(\mathrm{Pt})$, glassy carbon, gold $(\mathrm{Au})$, copper $(\mathrm{Cu})$, and transition metal oxide electrodes. However, the main restriction of this method is that it is susceptible to contaminations, which reduces the accuracy and sensitivity. Therefore, modified electrodes with different nanomaterials (metal, carbon, and polymeric) and their nanocomposites are proposed as alternative strategies to improve the performance of designed electrodes for nitrate detection in food samples. These electrodes electrochemical response to $\mathrm{NO}_{2}{ }^{-}$have high redox and increase the detection range and lower detection limit (LOD) for $\mathrm{NO}_{2}^{-}$[3]. Furthermore, modified electrodes with nanomaterials and their nanocomposites have high electrical conductivity, good resistance to heat and corrosion, good physicochemical stability, and large specific surface area. In recent years, among modified electrodes, electrochemical sensors based on graphene are of more attention due to their good catalytic ability, large surface area, high conductivity, and [1] and metal nanoparticle have been further developed due to their unique physicochemical characteristics, small size, and the high surface-to-volume ratio [2]. Although, throughout the past decade, several reviews were presented on modified electrochemical sensors. However, our main goal is focusing on the sensors that are exclusively modified using metal and graphene-based nanoparticles, specifically the detection of nitrate and nitrite in food samples. A brief comparison of their electrolyte $\mathrm{pH}$, detection limit, range of detection, sensitivity, and stability is made.

\section{Materials and Methods}

In this research, we study electrodes modified with metal and graphene nanoparticles and metal/graphene nanocomposites to detect nitrate/nitrite in food samples. For this reason, the Google Scholar, Science Direct, and Pup Med databases and articles of 2000 till 2020 have been searched with keywords "nitrite", "nitrate", "modified electrodes", "graphene", "metal nanoparticles" and "food sample", then their electrolyte $\mathrm{pH}$, the limit of detection, range of detection, sensitivity and stability was compared. 


\section{Results and Discussion}

\subsection{Modify the electrode with graphene-based nanoparticles.}

Using graphene as a matrix for electrochemical biosensors has attracted remarkable interest. Graphene sheets used to modify the sensors have some advantages, such as increasing the surface area of sensors, immobilizing a major amount of enzymes, antibodies, cells, or probe ssDNAs, and enhancing the received electrochemical response [10]. Graphene is formed of monolayers of carbon atoms that are arranged in a hexagonal configuration, the basic building block of graphite [11]. Graphene is known for its large surface area, controllable properties, and high electrical and thermal conductivity. It is considered a suitable material for designing electrochemical sensors [12]. Also, this material can be used in various fields. Figure 1.

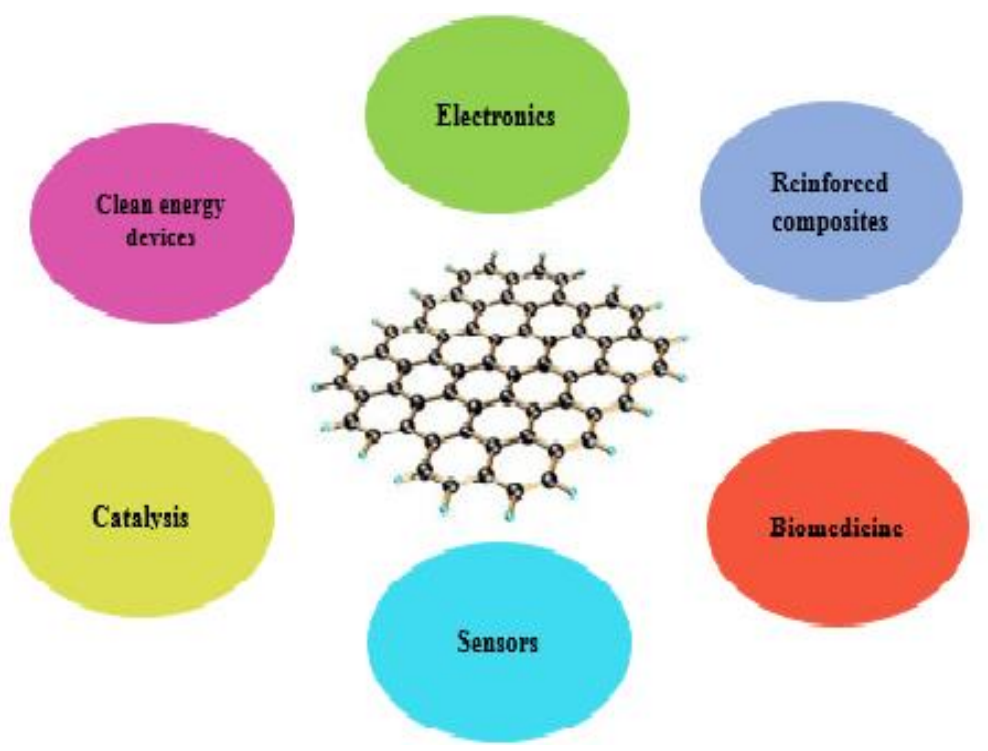

Figure 1. Graphene applications in various fields.

One remarkable advantage of graphene over fullerenes and carbon nanotubes is that graphene can be synthesized readily at a low cost in chemical laboratories [13]. On the other hand, the graphene particles' electron transferring ability is almost 60 times more than singlewalled carbon nanotubes. The conductance conductivity property of graphene is different according to treatment methods, preparation, and graphene particles' morphology. There are various methods for graphene synthesis such as; exfoliation and cleavage of natural graphite, chemical vapor deposition, plasma-enhanced chemical vapor deposition, electric arc discharge, micromechanical exfoliation of graphite epitaxial growth on electrically insulating surfaces, like opening carbon nanotube, silicon carbide, and solution-based reduction of graphene oxide [10]. Modified electrodes by graphene or nanocomposites based on graphene have many applications due to their high surface to volume ratio, high conductivity, and well catalytic ability [14]. Among the graphene family, graphene oxide (GO) and reduced graphene oxide (rGO) are extensively used as modifier substances in nitrite sensors. Mani et al. could fabricate nitrite sensors by chemically reduced graphene oxide with a sensitivity of $0.0267 \mathrm{~A} \mathrm{M}^{-1}$, the linear range of $8.9-167 \mu \mathrm{M}$ and LOD of $1 \mu \mathrm{M}$ [15]. In electrochemical reduced holey graphene (ERHG), the number of exposed edge planes, defect density, and the electron-transfer rate was increased remarkably. Jing Zhang et al. fabricated an electrode by ERHG to detect nitrite. Results showed that the electrode has LOD of $0.054 \mu \mathrm{M}$ and excellent stability [16]. Graphene nanoribbons (GNs) have reactive edges that can enhance the electrocatalytic properties and 
adsorption of molecules used in the electrode. Mehmeti et al. used graphene nanoparticles (GN/GCE) for nitrite detection in water samples. The proposed electrode had LOD of $0.22 \mu \mathrm{M}$, detection range from 0.5 to $105 \mu \mathrm{M}$, and well stability [14]. Doping of graphene with heteroatoms such as $\mathrm{S}, \mathrm{N}, \mathrm{K}$, and $\mathrm{P}$ is a way to develop its structural and electrochemical performances. Moreover, the electronic properties, chemical activities, and optical properties of graphene increase by chemical doping with heteroatoms like nitrogen ( $\mathrm{NrGO})$. Chen et al. used metal-free nitrogen-doped reduced graphene oxide (NrGO) for nitrite detection in food; the results showed that the designed electrode has a detection limit of $0.2 \mu \mathrm{M}$, detection range of $0.5-5000 \mu \mathrm{M}$, good sensitivity, and good stability [17]. The electrochemically activated graphite (EAG) had more surface area and high-energy adsorption sites that act as reservoirs for the rapid diffusion of the target molecule on the electrode surface. Selvakumar Palanisamy et al., used EAG to detect nitrite; this electrode had LOD of $38 \mathrm{nM}$, sensitivity $0.126 \mu \mathrm{A} \mu \mathrm{M}^{-1}$ $\mathrm{cm}^{-2}$, wider detection range, and excellent stability [18]. Table 1 shows the stability, sensitivity, and limitation in detecting electrodes modified with graphene nanoparticles for sensing of nitrate and nitrite in food samples.

\subsection{Modify the electrode by the metal nanoparticle.}

Metal nanoparticles have been extensively used for designing biosensors due to their unique catalysis properties and biocompatibility. For example, sensors based on gold nanoparticles to determine biological materials have received much attention due to their good stability-figure 2 [19].

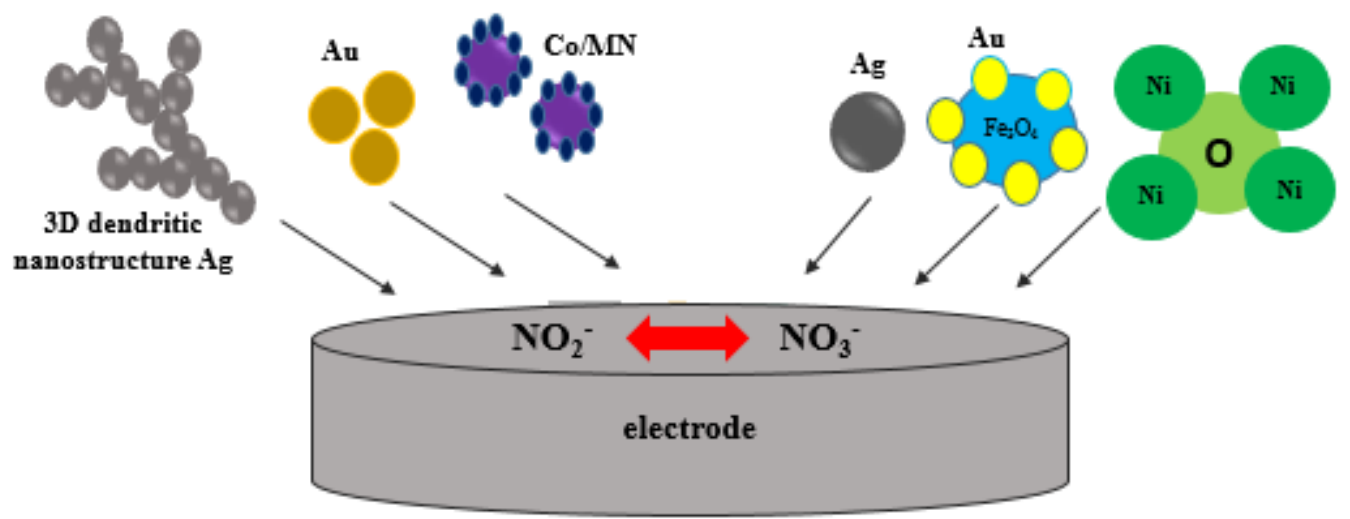

Figure 2. Modify the electrode by the metal nanoparticle.

Chen et al. used Au nanoparticles for nitrite detection. Modified electrodes had LOD of $82 \mathrm{nM}$, detection range from $0.1-4000$ and $4000-10000 \mu \mathrm{M}$, high sensitivity, and good stability [20]. Wan et al. designed electrodes with Au nanoparticles on a carbon paper electrode and investigated their electrochemical behaviors. Results showed LOD of $0.093 \mu \mathrm{M}$ and higher sensitivity for the designed electrode [21], also Wang et al. produced Au nanoparticles on choline chloride. It was shown that the modified electrode has LOD of $1.0 \times 10^{-7} \mathrm{M}$, a sensitivity of $0.354 \mu \mathrm{A} \mu \mathrm{M}^{-1}$, and a linear range of $4.0 \times 10^{-7}$ to $7.5 \times 10^{-4} \mathrm{M}$ [22]. Yu et al. used $\mathrm{Au}-\mathrm{Fe}_{3} \mathrm{O}_{4}$ nanoparticles as a modified electrode with a linear range of $3.6 \times 10^{-6}$ to $1.0 \times 10^{-2} \mathrm{M}$, and LOD of $8.2 \times 10^{-7} \mathrm{M}$; also, this electrode has good stability and selectivity [23]. Huang et al. modified an electrode with Au-copper nanochain on glassy carbon electrode with LOD of $0.2 \mu \mathrm{M}$, the linear range of 0.01 to $4.0 \mathrm{mM}$, the sensitivity of $17.55 \mu \mathrm{A} \mathrm{mM}-1$, and excellent stability [24]. Shen Liu et al. designed a sensor for detection of nitrite by $\mathrm{Au}-\mathrm{Fe}$ (III) nanoparticles and 
differential pulse voltammetry (DPV) with LOD of $2.0 \times 10^{-7} \mathrm{M}$, and amperometric results showed LOD of $1.0 \times 10^{-7} \mathrm{M}$ [25]. Comparison of electrodes modified with Au nanoparticles showed that the electrode modified with Au nanoparticles on the surface of choline chloride had the lowest detection limit. The most stable was the Au /copper modified electrode. Magnetic nanoparticles have been used as supports and carriers in biosensors for food safety assessment due to wide surface area and well biocompatibility [26]. Parsaei et al. used cobalt (II)-Schiff base complex and magnetite nanospheres to detect nitrite in water samples. The designed sensor had LOD of $1.5 \times 10^{-2} \mu \mathrm{mol} \mathrm{L}{ }^{-1}$, detection range from 0.2 to $30.0 \mu \mathrm{mol} \mathrm{L} \mathrm{L}^{-1}$, good sensitivity, and stability [27]. Dhanya et al. synthesized silver nanoparticles and used them to detect nitrite; the sensor was shown to have LOD of $1.5 \times 10^{-15} \mathrm{~mol} \mathrm{dm}^{-3}$ and high sensitivity [28]. Guadagnini et al. modified carbon electrodes with silver nanoparticles to determine nitrite and nitrate; the designed electrode had LOD of $3.7 \times 10^{-6} \mathrm{M}$ and $4.0 \times 10^{-6}$ $\mathrm{M}$, respectively, and low stability and sensitivity [29]. Hu and coworkers designed a nitrite sensor by 3D dendritic nanostructure of silver, which had LOD of $2 \mu \mathrm{M}$, the sensitivity of 28.2 $\mathrm{mAmM}^{-1}$, and short-term stability [30]. Shivakumar et al. designed an electrochemical sensor to detect nitrite in water and sausage by silver nanoparticles with LOD $0.031 \mu \mathrm{M}$, the sensitivity of $580 \mathrm{~mA} \mathrm{mM}-{ }^{1} \mathrm{~cm}^{-2}$, and long-term stability [9]. In general, we can say that electrodes modified with Ag nanospheres by green synthesis had the highest LOD. Investigations showed that electrode modification with other metal or metal oxide nanoparticles such as $\mathrm{NiO}$ [31], copper, and $\mathrm{CuO}$ [32] had almost similar LOD, and Copper-Cobalt nanoparticles had the highest LOD for nitrite oxidation; also $\mathrm{CuO}$ nano chains showed the highest stability. Table 2 shows the stability, sensitivity, and LOD of electrodes modified with metal nanoparticles for nitrate and nitrite detection in food samples.

\subsection{Modify electrode by metal nanoparticle/graphene-based nanocomposites.}

Nanocomposites are a combination of two or more different nanoparticles that can strengthen the weak points of an electrode and improve the electrode properties, including physical, chemical, thermodynamic, magnetic, electrochemical, and stability properties [34]. There are many studies about applying graphene/metal nanocomposites in biosensors' design to determine nitrite in food samples. In these biosensors, graphene sheets act as a substrate with high specificity to accommodate final biomolecules. Also, they facilitate transferring the electrons between the electrode and the analyte. Figure 3 [39]. Here we refer to electrodes that are modified using metal and graphene composites.

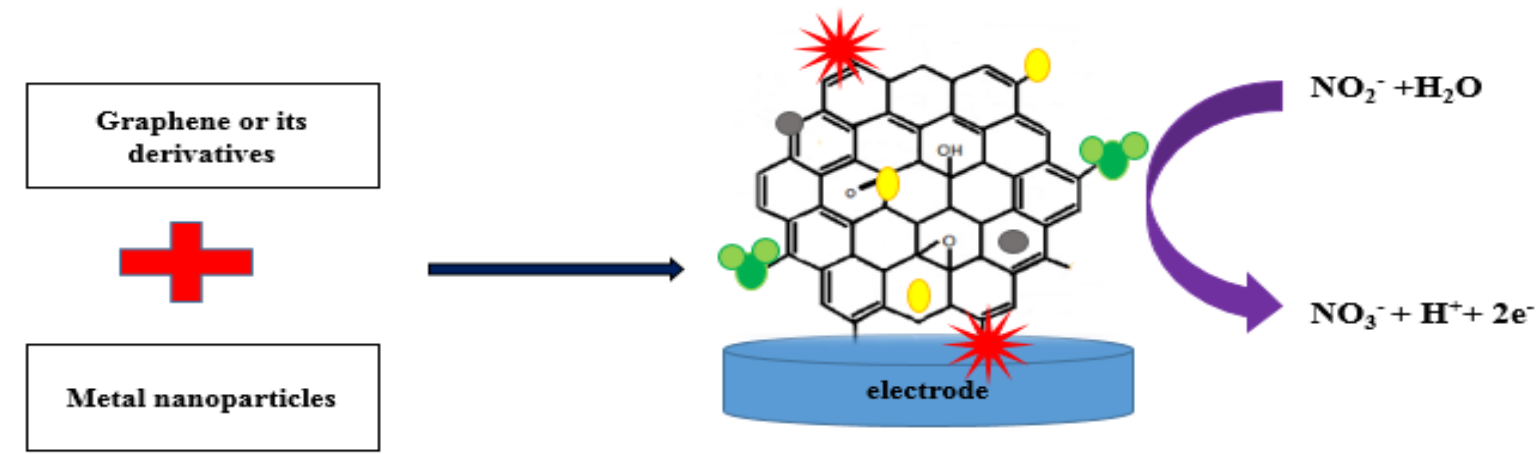

Figure 3. Modify electrode by metal nanoparticle/ Graphene-based nanocomposites. 


\subsubsection{Au nanoparticle/graphene-based nanocomposites.}

Research has shown that Au NPs/Gr nanocomposites have been the most favored candidates for nitrite sensing. Therefore several nanocomposites of Au have been developed to detect nitrite such as AuNPs/Gr/GCE [40], ERGO/Au NPs /SPCE [41], Au/f-GE/GCE [42], w-GN/Au/GCE [43], Au-HNTs-GO/GCE [44], Au At $_{1}$ NPs/PyTSNG/GCE [45] and $\mathrm{AuPd} / \mathrm{rGO} / \mathrm{GCE}$ [46]. Electrochemically reduced graphene oxide sheets provide a threedimensional structure for AuNPs attachment and nitrite absorption and catalyze its oxidation. For example, ERGO/AuNPs /SPCE modified electrode has a low LOD of $0.13 \mu \mathrm{M}$, a wide linear range, high sensitivity, and good stability. Therefore, it was a useful tool for detecting nitrite in various real food samples [41]. ZON et al. have shown that the spherical $\mathrm{Au}$ nanoparticles/3D flower-like network of graphene represents a great electrochemical ability in the oxidation of nitrite in pickled pork samples, with LOD of $0.01 \mu \mathrm{M}$, detection range of 0.125 to $20375.98 \mu \mathrm{M}$, and excellent stability [42]. Wavy graphene(W-GN) has a disordered structure with side and dangling bonds, which creates a high electrochemical catalytic activity. The electrode surface modification using w-GN/Au/GCE showed that the current reaction of nitrite is better than bare electrode, so the electrode has LOD of $6.0 \times 10^{-8}$ molL ${ }^{-1}$, good selectivity, powerful catalytic activity, wide linear range, and almost good stability [43]. Halloysite nanotubes (HNTs) are considered as a novel kind of natural nanotubes because of their low price and high length-to-diameter (L/D) ratio, and they have been attracted by researcher's attention for electrodes' designing. Also, there are hydroxyl groups on the HNTs surface that metal nanoparticles can grow directly on its surface. Zhang et al. synthesized AuHNT-GO nanocomposites for fabricating an electrochemical sensor for nitrite detection in tap water. The results indicated that the sensor has excellent performance, LOD of $0.03 \mu \mathrm{M}$, the sensitivity of 0.0231 to 0.0865 , good reproducibility, and long-term stability [44]. Li et al. decorated Au-Pt bimetallic nanoparticles (Au-PtNPs) on the surface of NG with 1, 3, 6, 8pyrene tetra sulfonic acid sodium salt. The sensor had a linear range of $0.5-1621 \mu \mathrm{M}$ and LOD of $0.19 \mu \mathrm{M}$ to detect nitrite in ham sausage samples. The current response is also decreased $5.7 \%$ of its original response after two weeks [45]. Li et al. synthesized $\mathrm{Au}-\mathrm{Pd}$ nanoparticles to design $\mathrm{Au}-\mathrm{Pd} / \mathrm{rGO} / \mathrm{GCE}$ electrodes for nitrite detection in tap water. This electrode had LOD of $0.02 \mu \mathrm{M}$, good reproducibility, a linear range of 0.05-1000.0 M, and good stability [46]. Results showed that the electrode of Au nanoparticles/3D flower-like network graphene represents the lowest LOD, and ERGO/AuNPs /SPCE electrode has the highest stability among the designed sensors nitrite [41].

\subsubsection{Pt nanoparticle/graphene-based nanocomposites.}

Researches showed that platinum $(\mathrm{Pt})$ morphology has a remarkable impact on nitrite detection [47]. On the other hand, platinum/graphene composite had more impact on nitrite oxidation due to its high catalytic sites. PtNPs prevent graphene agglomeration and have a synergistic effect on the oxidation of nitrite. Therefore, different platinum composites have been used to detect nitrite in food samples, such as Pt-RGO/GCE [48], Pt-ErGO/GCE [49], Ni$\mathrm{Pt} / \mathrm{Gr} / \mathrm{GCE}$ [50], Co-Pt/Gr/GCE [51], Cu-Pt/Gr/GCE [52]. Yang et al. deposited platinum nanoparticles on a reduced graphene surface. The amperometry results showed that the PtRGO modified electrode has LOD of $0.1 \mu \mathrm{M}$, detection range of $0.25-90 \mu \mathrm{M}$, and sensitivity of $0.4964 \mu \mathrm{A} \mathrm{mM}^{-1}$. Also oxidation current response remained $95.2 \%$ after 15 days [48]. As metal nanoparticles can improve the conductivity and catalytic potential of ErGO, Vijayaraj et 
al. modified ErGO surface by platinum nanocomposites film for nitrite detection in tap water. The electrochemical results indicated that the modified electrode has LOD of $0.22 \mu \mathrm{M}$. Linear ranges of 5-100 mM and 100-1000 $\mathrm{mM}$ and oxidation current response remained $99.8 \%$ after 6 days and $90.02 \%$ after 12 days [49]. One of the reasons for using double metal composite, except the synergistic effect of metals on the catalyst activity, was to overcome the cost of using one expensive metal. The electrochemical results show that the electrode modified with $\mathrm{Ni}-\mathrm{Pt} / \mathrm{Gr} / \mathrm{GCE}$ had better catalytic performance than Pt/Gr. Hameed et al. used Ni-Pt/Gr/GCE, $\mathrm{Co}-\mathrm{Pt} / \mathrm{Gr} / \mathrm{GCE}$, and $\mathrm{Cu}-\mathrm{Pt} / \mathrm{Gr} / \mathrm{GCE}$ to detect nitrate in tap and river water samples. The electrochemical results showed LOD of $0.49,0.145$, and $0.035 \mu \mathrm{M}$, the sensitivity of 0.08518 , 0.04596- 0.09771, and 0.2103-0.6269, the detection range of 10-15000, 1-2000; 2000-15000 and 1-1000, and 1000-15000 $\mu \mathrm{M}$, respectively and excellent stability for the electrodes. Results showed that $\mathrm{Cu}-\mathrm{Pt} / \mathrm{Gr} / \mathrm{GCE}$ electrode has the lowest LOD and Co-Pt/Gr/GCE electrode has the highest stability.

\subsubsection{Pd nanoparticle/ Graphene-based nanocomposites.}

Palladium (Pd) nanoparticles are widely used due to their excellent conductivity, relatively low price, well electrocatalytic performance, and high chemical inertness [53]. Fu et al. designed nanoparticles of Pd and reduced graphene oxide (RGO) electrode for nitrite detection. The results showed that $\mathrm{Pd}$ and graphene nanoparticles have a synergistic effect on nitrite oxidation. This electrode had a detection range of $1-1000 \mu \mathrm{M}$, and LOD of $0.23 \mu \mathrm{M}$, also oxidation current response remained $94 \%$ after one hour [54]. Zhao et al., a modified electrode with $\mathrm{Pd} / \mathrm{Fe} 3 \mathrm{O} 4 /$ polyDOPA/RGO to detect nitrite in river water and sausage. The amperometric response showed LOD of $0.5 \mu \mathrm{M}$, and a detection range of $2.5-6470 \mu \mathrm{M}$, also oxidation current response remained $90 \%$ after 9 days [55]. Results showed that $\mathrm{Pd} / \mathrm{rGO} / \mathrm{GCE}$ electrode has the lowest LOD, and Pd/Fe3O4/polyDOPA/RGO/GCE electrode has the highest stability.

\subsubsection{Ag nanoparticle/graphene-based nanocomposites.}

Silver nanoparticles have been widely used to prepare electrochemical sensors due to their biocompatibility, wide specific surface, and catalytic activity [56]. Ikhsan et al. designed a sensor with GO and Ag nanoparticles for nitrite detection in water, using LSV (Linear Sweep Voltammetry) and amperometric techniques. LOD values were 2.1 and $0.037 \mu \mathrm{M}$, and the detection ranges were 10-180, and 1-1000 $\mu \mathrm{M}$, respectively. The result showed that $95 \%$ of the electrode's stability has remained after one week [57]. Ahmad et al. synthesized silver and reduced graphene nanoparticles to modify the electrode's surface. The electrochemical results indicated a detection range of $0.1-120 \mu \mathrm{M}$, LOD of $0.012 \mu \mathrm{M}$, and sensitivity of 18.4. Also, $94.5 \%$ of the electrode's stability remained after 5 weeks [58]. $\mathrm{TiO}_{2}$ is widely used to prepare electrochemical sensors because it is cost-effective and has high conductivity and good biocompatibility. Zhang et al. used $\mathrm{Ag} / \mathrm{TiO}_{2} / \mathrm{r}-\mathrm{GO} / \mathrm{GCE}$ electrode for detection of nitrite in tap and rainwater; electrochemical results indicated that the modified electrode showed well electrocatalytic efficiency for the nitrite oxidation, the sensor had a LOD of $0.4 \mu \mathrm{M}$, the sensitivity of 0.112 , linear range $1-1100 \mu \mathrm{M}$ and the oxidation response retained $90 \%$ after three weeks [56]. Results showed that Ag-rGO/GCE electrode has the lowest LOD and the highest stability. 


\subsubsection{Cu nanoparticle/ Graphene-based nanocomposite.}

Wang et al., were designed an electrode with copper nanoparticles and graphene pallets for the determination of nitrate in river water and tap water samples. The amperometric results showed that the designed electrode has a detection range of $0.15-10500 \mu \mathrm{M}$, and LOD of 0.06 $\mu \mathrm{M}$. Also, the oxidation response remained $95.9 \%$ after 15 days [59]. Majidi et al. fabricated a nitrite sensor by $\mathrm{Cu}$ nanoporous film supported by the electrode of graphene nanosheets. The amperometric results confirmed the following results: The LOD was equal to 0.0887 , detection range $0.1-100 \mu \mathrm{M}$, sensitivity 3.1, and good stability [60]. Results showed that the modified $\mathrm{Cu} / \mathrm{f}-\mathrm{RGO} / \mathrm{GCE}$ electrode shows high electrocatalytic activity towards $\mathrm{Cu} / \mathrm{RGO} / \mathrm{GCE}$ and $\mathrm{Cu} / \mathrm{GCE}$. In addition to the facile preparation process, non-noble metal present in the electrode could decrease the preparation costs; this electrode had the lowest LOD and highest stability.

\subsection{Modify electrode by metal oxide nanoparticle/Graphene-based on nanocomposite.}

Crystal structure metal oxide nanoparticles have possessed high catalytic activity due to their high surface ratio to volume. On the other hand, hybridization of them with graphene could present higher electrocatalytic activity, larger specific surface area, and superior biocompatibility. As a result, they are used for designing electrochemical sensors to detect nitrite [61]

\subsection{1. $\mathrm{Fe}_{2} \mathrm{O}_{3}$ nanoparticle/Graphene-based nanocomposite.}

$\mathrm{Fe}_{2} \mathrm{O}_{3}$ nanoparticles have been used for electrochemical sensors' designing because of their low cost, well biocompatibility, excellent bandgap, and high catalytic activity [62], $\mathrm{Fe}_{2} \mathrm{O}_{3} / \mathrm{rGO}$ nanocomposite can inhibit the aggregation of rGO sheets by introducing $\mathrm{Fe}_{2} \mathrm{O}_{3} \mathrm{NPs}$ on the surface of rGO nanosheets. In this way, it can expend the surface area of composite in compare to $\mathrm{rGO}$ nanosheets alone. Also, Bharath et al. synthesized $\mathrm{rGO}-\mathrm{Fe}_{3} \mathrm{O}_{4}$ nanocomposites for detecting nitrite in the rain, tap, and river water. The modified sensor indicated good electrocatalytic activity and good stability, with a sensitivity of 0.2025 and low LOD [63].

\subsubsection{Ce nanoparticle/Graphene-based nanocomposite.}

Nanostructures of cobalt oxide are cheap and environment friendly also; they have well conductivity [64]. $\mathrm{Co}_{3} \mathrm{O}_{4}$ is extensively used to design electrochemical nitrite sensors due to its high surface area and well chemical stability. By considering the exceptional and unique properties of graphene and $\mathrm{Co}_{3} \mathrm{O}_{4}$, a combination of them might yield enhanced performance. The composite electrode showed high sensitivity, which detected a broad range of nitrite concentrations from 1 to $380 \mathrm{M}$ and had the lowest LOD (0.14 M) [65]. M.Stanković et al. compared the ability of cerium, titanium, and selenium dioxide nanoparticles for detecting nitrite in tap water. The suggested sensor acquires acceptable selectivity and sensitivity with a low LOD $(0.18 \mu \mathrm{M})$ and a broad linear range of 0.7 to $385 \mu \mathrm{M}$, under optimized operational circumstances [66]. Also, Luo et al. made a nitrite sensor with graphene oxide and cobalt hexacyanoferrate nanoparticles. The results obtained from DPV showed that the designed sensor has low LOD equal to $0.27 \mu \mathrm{M}$ and a linear range of 1 to $100 \mu \mathrm{M}$ [67]. 
Table 1. Application of electrochemical sensors based on graphene nanomaterial's in detection nitrite/nitrate.

\begin{tabular}{l|l|l|l|l|l|l|l|l} 
Formulation & Technique & Food sample & $\mathbf{p H}$ & Detection range & LM & Sensitivity & Stability \\
\hline GNs/GCE & Am & Tap Water & 3 & $0.5-105 \mu \mathrm{M}$ & $0.22 \mu \mathrm{M}$ & - & $5 \mathrm{~d}$ \\
\hline ERHG & Am & Tap water, Liquid milk & 7.4 & $0.2-10,000 \mu \mathrm{M}$ & $0.054 \mu \mathrm{M}$ & $0.311 \mu \mathrm{A} \mu \mathrm{M}^{-1} \mathrm{~cm}^{-2}$ & $95 \%$ remained after $3 \mathrm{w}$ \\
\hline NrGO & DPV & Pickled garlic, river water & 7 & $0.5-5000 \mu \mathrm{M}$ & $0.2 \mu \mathrm{M}$ & $0.229 \mu \mathrm{A} \mu \mathrm{M}^{-1} \mathrm{~cm}^{-2}$ & $93.8 \%$ remained after $30 \mathrm{~d}$ \\
\hline CR-GO/GCE & Am & Water & 5 & $8.9-167 \mu \mathrm{M}$ & $1 \mu \mathrm{M}$ & $0.0267 \mathrm{~A} \mathrm{M}^{-1}$ & $\left.\mathrm{decrease} \mathrm{in} \mathrm{the} \mathrm{response} \mathrm{after} 4 \mathrm{~d}^{[17}\right]$ & {$[15]$} \\
\hline EAG & Am & Water & - & $0.1 \mu \mathrm{M}$ to $16.4 \mathrm{mM}$ & $38 \mathrm{nM}$ & $0.126 \mu \mathrm{A} \mu \mathrm{M}_{-}^{-1} \mathrm{~cm}^{-2}$ & $96.4 \%$ remained after $24 \mathrm{~d}$
\end{tabular}

GCE: glassy carbon electrode/ CR-GO: chemically reduced graphene oxide, Am: Amperometry, DPV: Differential pulse voltammetry, LM: Limit of detection, d: day, w: week.

Table 2. Modification of electrodes using metal for detection nitrite/nitrate in a food sample.

\begin{tabular}{|c|c|c|c|c|c|c|c|c|}
\hline Formulation & Technique & Food sample & pH & Detection range & LM & Sensitivity & Stability & $\mathbf{R}$ \\
\hline Ag & SWV & Water & 4.5 & $10^{-14}$ to $10^{-6}(\mathrm{~mol} \mathrm{dm}-3)$ & $10^{-15}\left(\mathrm{~mol} \mathrm{dm}^{-3}\right)$ & high sensitivity & - & [28] \\
\hline $\mathbf{A u}-\mathbf{F e}(\mathrm{III})$ & DPV, Am & Water & 5 & $\begin{array}{l}\text { DPV:3.0 } 3 \times 10^{-7}-1.5 \times 10^{-4} \mathrm{M} \\
\text { Am: } 2.0 \times 10^{-7}-1.5 \times 10^{-4} \mathrm{M}\end{array}$ & $\begin{array}{l}\text { DPV: } 2.0 \times 10^{-7} \mathrm{M} \\
\text { Am: } 1.0 \times 10^{-7} \mathrm{M}\end{array}$ & - & $92 \%$ retained after $30 \mathrm{~d}$ & [25] \\
\hline $\mathbf{A g}$ & $\begin{array}{l}\mathrm{NO}_{2}^{-}: \mathrm{DPV} \\
\mathrm{NO}_{3}^{-}: \mathrm{CV}\end{array}$ & Water & 6.7 & $\begin{array}{l}\mathrm{NO}_{2}^{-}: 5.0 \times 10^{-6}-1.1 \times 10^{-3} \\
\mathrm{NO}_{3}^{-}:: 1.0 \times 10^{-5}-5.0 \times 10^{-3}\end{array}$ & $\begin{array}{c}\mathrm{NO}_{2}^{-}: 3.7 \times 10^{-6} \mathrm{M} \\
\mathrm{NO}_{3}^{-}:: 4.0 \times 10^{-6} \\
\end{array}$ & $\begin{array}{l}\mathrm{NO}_{2}^{-}: 790, \mathrm{NO}_{3}^{-}: \\
3400\left(\mathrm{AM}^{-1} \mathrm{~m}^{-2}\right)\end{array}$ & $1 \mathrm{~d}$ & [29] \\
\hline $\mathbf{A u}$ & DPV & Water, Sausage & 4 & $4.0 \times 10^{-7}$ to $7.5 \times 10^{-4} \mathrm{M}$ & $1.0 \times 10^{-7} \mathrm{M}$ & $0.354 \mu \mathrm{A} \mu \mathrm{M}^{-1}$ & $81 \%$ retained after $60 \mathrm{~d}$ & [22] \\
\hline $\mathbf{A g}$ & SWV & Water & 7 & $2-1000 \mu \mathrm{M}$ & $2 \mu \mathrm{M}$ & $28.2 \mathrm{mAmM}^{-1}$ & The short-term stability & [30] \\
\hline $\mathbf{A u}$ & $\mathrm{Am}$ & Water & 7 & $0.1-4000$ and $4000-10000 \mu \mathrm{M}$, & $82 \mathrm{nM}$. & $252 \mu \mathrm{A} \mathrm{mM}^{-1} \mathrm{~cm}^{-2}$ & $88 \%$ retained after $28 \mathrm{~d}$ & [20] \\
\hline $\mathbf{A g}$ & $\mathrm{Am}$ & Water, Sausage & 7 & $0.1^{-8} \mu \mathrm{M}$ & $0.031 \mu \mathrm{M}$ & $580 \mathrm{mAmM}^{-1} \mathrm{~cm}^{-2}$ & long-term stability & [9] \\
\hline $\mathrm{NiO}$ & SWV & Sausage, Pickled & 7 & $0.8-1100 \mu \mathrm{M}$ & $0.3 \mu \mathrm{M}$ & Good & $93 \%$ retained after $20 \mathrm{~d}$ & [31] \\
\hline CoL/MNSs & SWV & water & 4.5 & $0.2-30.0 \mu \mathrm{mol} \mathrm{L}^{-1}$ & $1.5 \times 10^{-2} \mu \mathrm{mol} \mathrm{L}^{-1}$ & $3.054 \mu \mathrm{AL} \mu \mathrm{mol}^{-1}$ & $85 \%$ retained after $90 \mathrm{~d}$ & [27] \\
\hline Gd/TiO 2 & $\mathrm{CV}$ & sausage & 7 & $5.0 \times 10^{-7} \mathrm{~mol} \mathrm{l}^{-1}$ & $8.0 \times 10^{-7}$ to $4.0 \times 10^{-4} \mathrm{~mol} \mathrm{l}^{-1}$ & - & $94 \%$ retained after $14 \mathrm{~d}$ & [33] \\
\hline Au & $\mathrm{Ca}$ & water & 7 & $1-100 \mu \mathrm{M}$ & $0.093 \mu \mathrm{M}$ & $\begin{array}{c}0.08138 \mathrm{~mA} \mathrm{mM}^{-1} \\
\& 0.0476 \mathrm{~mA} \mathrm{mM}^{-1}\end{array}$ & $28 \mathrm{~d}$ & [21] \\
\hline $\mathrm{Fe}_{3} \mathrm{O}_{4} @ \mathrm{Pt}$ & $\mathrm{DPV}, \mathrm{Am}$ & Water, orange juice & 4 & $3.3 \times 10^{-7}$ to $1.3 \times 10^{-2} \mathrm{M}$ & $1.09 \times 10^{-7} \mathrm{M}$ & - & $93 \%$ retained after $21 \mathrm{~d}$ & [34] \\
\hline Alumina & Am, DPV & Sausage & 5 & $5.0 \times 10^{-8}-1.1 \times 10^{-3} \mathrm{~mol} \mathrm{~L}^{-1}$ & $1.0 \times 10^{-8} \mathrm{~mol} \mathrm{~L}^{-1}$ & - & $14 \mathrm{~d}$ & [35] \\
\hline $\mathbf{A u} @ \mathrm{Fe}_{3} \mathrm{O}_{4}$ & DPV & Sausage & 4 & $3.6 \times 10^{-6}$ to $1.0 \times 10^{-2} \mathrm{M}$ & $8.2 \times 10^{7} \mathrm{M}$ & - & $95 \%$ remained after $15 d$ & [23] \\
\hline $\mathrm{CuO}$ & $\mathrm{CV}$ & picked vegetables & 7.5 & $0.004-3.7 \mathrm{mM}$ & $0.3 \mu \mathrm{M}$ & $\begin{array}{c}177.9 \mu \mathrm{Amg}^{-1} \mathrm{dL}^{-1} \\
\mathrm{~cm}^{-2}\end{array}$ & $98.5 \%$ remained after $30 \mathrm{~d}$ & [32] \\
\hline Au-Coper & DPV & Water & 7 & $0.01 \sim 4.0 \mathrm{mM}$ & $0.2 \mu \mathrm{M}$ & $0.0176 \mu \mathrm{A} \mu \mathrm{M}^{-1}$ & $98.60 \%$ remained after $35 d$ & [24] \\
\hline Pd-Fe & $\mathrm{Am}$ & Water & 4 & $6 \times 10-^{6}-5 \times 10-^{3} \mathrm{M}$ & $2 \times 10^{6} \mathrm{M}$ & - & - & [36] \\
\hline TO & LSV, CV & Sausage & 6 & $5 \times 10^{-7}-1.5 \times 10^{-3} \mathrm{M}$ & $2 \times 10^{-7} \mathrm{M}$ & - & $97.1 \%$ remained after $14 \mathrm{~d}$ & [37] \\
\hline Copper-cobalt & $\mathrm{Am}$ & Sausages & 7.4 & 0.5 to $430 \mu \mathrm{M}$ & $60 \mathrm{nM}$ & - & $96 \%$ remained after $30 \mathrm{~d}$ & [38] \\
\hline
\end{tabular}

TO: Titanium Dioxide, Co/MNS: cobalt (II)/Magnetite nanospheres, Ca: Chronoamperometry, SWV: Squarewave voltammetry, LSV:

Linear Sweep Voltammetry 


\begin{tabular}{|c|c|c|c|c|c|c|c|c|}
\hline Formulation & Technique & Food Sample & pH & Detection range & LM & Sensitivity & Stability & $\mathbf{R}$ \\
\hline Au NPs/Gr/GCE & Am & Sausage, packaged & 3 & $5 \times 10^{-5}$ to $5.1 \times 10^{-3} \mathrm{M}$ & $0.016 \mathrm{mM}$ & - & $93 \%$ after $2 \mathrm{~d} / 85 \%$ after $60 \mathrm{~d}$ & [40] \\
\hline ERGO/Au NPs /SPCE & DPV & Water, Shrimps, Fish, Sausages & 2 & $1-6000 \mu \mathrm{M}$ & $0.13 \mu \mathrm{M}$ & $0.3048 \mu \mathrm{A} \mu \mathrm{M}^{-1} \mathrm{~cm}^{-2}$ & $93 \%$ after $60 \mathrm{~d}$ & [41] \\
\hline Au/f-GE/GCE & DPV & Pickled pork & 7 & $0.125-20375.98 \mu \mathrm{M}$ & $0.01 \mu \mathrm{M}$ & - & $96.03 \%$ after $100 \mathrm{~d}$ & [42] \\
\hline w-GN/Au/GCE & DPV & Tap Water, Sausage & 7.2 & $1 \times 10^{-7}$ to $5 \times 10^{-3} \mathrm{~mol} \mathrm{~L}^{-1}$ & $6 \times 10^{-8} \mathrm{~mol} \mathrm{~L}^{-1}$ & - & $97 \%$ after 2 day- $95 \%$ after $7 \mathrm{~d}$ & [43] \\
\hline Au-HNTs-GO/GCE & $\mathrm{Am}$ & Tap water & 6 & $0.1-6330 ; 330-61900 \mathrm{mM}$ & $0.03 \mu \mathrm{M}$ & $0.023 ; .0865 \mu \mathrm{A} \mathrm{m}$ & $93 \%$ after $7 \mathrm{~d}$ & [44] \\
\hline $\mathrm{Au}_{2} \mathrm{Pt}_{\mathbf{1}} \mathbf{N P s} / \mathbf{P y T S N G / G C E}$ & $\mathrm{Am}$ & Ham sausage & - & $0.5-1621 \mu \mathrm{M}$ & $0.19 \mu \mathrm{M}$ & $0.0276 \mu \mathrm{A} \mathrm{\mu M}^{-1}$ & $94.3 \%$ after 14 days & [45] \\
\hline Au-Pd/rGO/GCE & $\mathrm{Am}$ & Tap water & 7 & $0.05-1000 \mu \mathrm{M}$ & $0.02 \mu \mathrm{M}$ & - & $85 \%$ after $5 d-75 \%$ after $10 d$ & [46] \\
\hline Pt-RGO/GCE & $\mathrm{Am}$ & Beverage & 7 & $0.25-90 \mu \mathrm{M}$ & $0.1 \mu \mathrm{M}$ & $0.4964 \mu \mathrm{A} \mu \mathrm{M}^{-1}$ & $95.2 \%$ After $15 \mathrm{~d}$ & [48] \\
\hline Pt-ErGO/GCE & $\mathrm{Am}$ & Tap Water & 5 & $5-100 ; 100-1000 \mu \mathrm{M}$ & $0.22 \mu \mathrm{M}$ & - & $99.8 \%$ after $6 \mathrm{~d} 90.02 \%$ after $12 \mathrm{~d}$ & [49] \\
\hline $\mathrm{Ni} @ \mathrm{Pt} / \mathrm{Gr} / \mathrm{GCE}$ & $\mathrm{Am}$ & Tap and river water & 4 & $10 \mu \mathrm{M}-15 \mathrm{mM}$ & $0.49 \mu \mathrm{M}$ & $85.18 \mu \mathrm{A} \mathrm{\mu M}^{-1} \mathrm{~cm}^{-2}$ & $90.23 \%$ after $21 \mathrm{~d}$ & [50] \\
\hline Co@Pt/Gr/GCE & $\mathrm{Am}$ & Tap and river water & 6 & $2-15 \mathrm{mM}$ & $0.145 \mu \mathrm{M}$ & $97.71 \mu{\mathrm{A} \mu \mathrm{M}^{-1} \mathrm{~cm}^{-2}}^{2}$ & $87.12 \%$ after $30 \mathrm{~d}$ & [51] \\
\hline $\mathbf{C u} @ \mathbf{P t} / \mathbf{G r} / \mathbf{G C E}$ & $\mathrm{Am}$ & Tap and river water & 4 & $1 \mu \mathrm{M}^{-1} \mathrm{mM} ; 1 \mathrm{mM}^{-15} \mathrm{mM}$ & $0.035 \mu \mathrm{M}$ & $0.21 ; 0.6269 \mu \mathrm{A} \mu \mathrm{M}^{-1} \mathrm{~cm}^{-2}$ & $86.87 \%$ after $30 \mathrm{~d}$ & [52] \\
\hline Pd/rGO/GCE & DPV & - & 7 & $1-1000 \mu \mathrm{M}$ & $0.23 \mu \mathrm{M}$ & - & $94 \%$ after one hour & [54] \\
\hline $\begin{array}{l}\mathrm{Pd} / \mathrm{Fe}_{3} \mathrm{O}_{4} / \text { polyDOPA} / \\
\mathrm{RGO} / \mathrm{GCE}\end{array}$ & $\mathrm{Am}$ & Yellow River water, sausage & 7.4 & $2.5-6470 \mu \mathrm{M}$ & $0.5 \mu \mathrm{M}$ & - & $90 \%$ after $9 \mathrm{~d}$ & [55] \\
\hline GO-Ag/GCE & $\mathrm{LSV}, \mathrm{Am}$ & Lake water & 7.2 & & $37 \mu \mathrm{M}$ & - & $95 \%$ after $7 \mathrm{~d}$ & [57] \\
\hline Ag-rGO/GCE & DPV & water & 7.4 & $0.1-120 \mu \mathrm{M}$ & $0.012 \mu \mathrm{M}$ & $18.4 \mu \mathrm{A} \mu \mathrm{M}^{-1} \mathrm{~cm}^{-2}$ & $94.5 \%$ after $35 \mathrm{~d}$ & [58] \\
\hline $\mathrm{Ag} / \mathrm{TiO}_{2} / \mathrm{r}-\mathrm{GO} / \mathrm{GCE}$ & $\mathrm{Am}$ & Tap Water, Rain Water & 7.1 & $1 \mu \mathrm{M}-1.1 \mathrm{mM}$ & $0.4 \mu \mathrm{M}$ & $112.0 \mu \mathrm{A} \mu \mathrm{M}^{-1} \mathrm{~cm}^{-2}$ & $90 \%$ after $21 \mathrm{~d}$ & [56] \\
\hline Cu/f-RGO/GCE & $\mathrm{Am}$ & river water and tap water & 2 & $0.15-10500 \mu \mathrm{mol} \mathrm{L}^{-1}$ & $0.06 \mu \mathrm{mol} \mathrm{L}^{-1}$ & - & $95.9 \%$ after $15 \mathrm{~d}$ & [59] \\
\hline NPCu/GNs/GCE & $\mathrm{Am}$ & tap, river water, sausage & & $1 \times 10^{-7}-1 \times 10^{-4} \mathrm{~mol} \mathrm{~L}^{-1}$ & $8.87 \times 10^{-8} \mathrm{~mol} \mathrm{~L}^{-1}$ & $3.1 \mathrm{AL} / \mathrm{mol} \mathrm{cm}^{2}$ & No significant & [60] \\
\hline $\mathrm{Fe}_{3} \mathrm{O}_{4} / \mathrm{RGO} / \mathrm{GCE}$ & $\mathrm{Am}$ & & 4 & $0.5-780 \mu \mathrm{M}$ & $0.015 \mu \mathrm{M}$ & $0.204 \mu \mathrm{A} / \mu \mathrm{M}$ & $92.36 \%$ after $25 \mathrm{~d}$ & [63] \\
\hline $\mathrm{Co}_{3} \mathrm{O}_{4} / \mathrm{RGO} / \mathrm{GCE}$ & $\mathrm{Am}$ & Tap water & - & $1-380 \mu \mathrm{M}$ & $29.5 \mu \mathrm{M}$ & $0.14 \mu{\mathrm{A} \mu \mathrm{M}^{-1} \mathrm{~cm}^{-2}}^{2}$ & high stability & [65] \\
\hline $\mathrm{CeO} / \mathrm{rGO} / \mathrm{GCE}$ & Am & Tap water & & $0.7-385 \mu \mathrm{M}$ & $0.18 \mu \mathrm{M}$ & - & - & [66] \\
\hline CoHCF-rGO/GCE & DPV & Tap and river water & 6.5 & $1-100 \mu \mathrm{M}$ & $0.27 \mu \mathrm{M}$ & - & - & [67] \\
\hline MnO2/GO-SPE & DPV & Tap water, Packaged water & 7.4 & $0.1-1000 \mu \mathrm{M}$ & $0.09 \mu \mathrm{M}$ & - & No significant after 3-4 m & [70] \\
\hline GO/Mn ${ }_{3} \mathrm{O}_{4} \mathrm{MC} / \mathrm{SPE}$ & $\mathrm{Am}$ & Beef \& drinking water & 7 & $0.1-1300 \mu \mathrm{M}$ & $0.02 \mu \mathrm{M}$ & $2.37 ; 1.23 \mu \mathrm{A} \mu \mathrm{M}^{-1} \mathrm{~cm}^{-2}$ & $97.8 \%$ after $30 \mathrm{~d}$ & [71] \\
\hline Fe-ZnO@rFGO/GCE & $\mathrm{Am}$ & River, Lake, Sea, Tap water & 7.2 & $10-5000 \mu \mathrm{M}$ & $33 \mu \mathrm{M}$ & & no significant & \\
\hline Ag-AEfG & $\mathrm{Am}$ & tap water & 7.4 & $0.05-3000 \mu \mathrm{M}$ & $0.023 \mu \mathrm{M}$ & $200 \mu \mathrm{A} \mu \mathrm{M}^{-1} \mathrm{~cm}^{-2}$ & $98.7 \%$ & [74] \\
\hline $\mathrm{Au} / \mathrm{GO}-\mathrm{CS} / \mathrm{GCE}$ & Am & water & 5 & $0.9-18.9 \mu \mathrm{M}$ & $0.3 \mu \mathrm{M}$ & & - & [75] \\
\hline Fe3O4 /GO/COOH/GCE & DPV & water & 4 & $1-8590-600 \mu \mathrm{M}$ & $0.37 \mu \mathrm{M}$ & $0.192 \mu \mathrm{A} \mu \mathrm{M}^{-1}$ & - & [76] \\
\hline Au/Cu-TDPAT/ERGO/GCE & DPV & food & 7 & $0.001-1000 \mu \mathrm{M}$ & $0.006 \mu \mathrm{M}$ & - & $95 \%$ after $6 \mathrm{~d}$ & [77] \\
\hline Fe2O3/H-C3N4 /RGO & $\mathrm{Am}$ & - & 7.4 & $0.025-3000$ & $0.0186 \mu \mathrm{M}$ & $0.0487 \mu \mathrm{A} \mu \mathrm{M}^{-1}$ & $98 \%$ after $15 \mathrm{~d}$ & [78] \\
\hline CuOx/ERGO & $\mathrm{Am}$ & Food & 4 & $0.1-100$ & $0.072 \mu \mathrm{M}$ & - & - & [79] \\
\hline TiO2 /RGO & DPV & water & 7 & $1-1000 \mu \mathrm{M}$ & $0.21 \mu \mathrm{M}$ & - & - & [80] \\
\hline $\mathrm{Ni}(\mathrm{OH}) 2 /$ RGO & $\mathrm{Am}$ & water & 7 & $0.1-663.6 \mu \mathrm{M}$ & $0.07 \mu \mathrm{M}$ & $21.93 \mu \mathrm{A} \mu \mathrm{M}^{-1}$ & $90 \%$ after $10 \mathrm{~d}$ & [81] \\
\hline RGO/MnFe2O4/PANI & DPV & water & 7 & $0.05-12000 \mu \mathrm{M}$ & $0.015 \mu \mathrm{M}$ & & $93 \%$ after $30 \mathrm{~d}$ & [82] \\
\hline rGO/ZnO/GCE & LSV/Am & water & 7.1 & $200-4000 / 20-520 \mu \mathrm{M}$ & $1.18 / 1.36 \mu \mathrm{M}$ & $\begin{array}{l}0.3156 / 0.2754 \mathrm{mAmM}^{-1} \mathrm{~cm}^{-2} \\
1522.5 \mu \mathrm{mM}^{-1} \mathrm{~cm}^{-2}\end{array}$ & $97.55 \%$ & [83] \\
\hline Cu-MOF-GO/GCE & $\mathrm{Am}$ & water & 7.2 & $1 \times 10^{-8}$ to $1 \times 10^{-4} \mathrm{M}$ & $470.001 \mu \mathrm{M}$ & & $98.2 \%$ after $10 \mathrm{C}$ & [84] \\
\hline
\end{tabular}

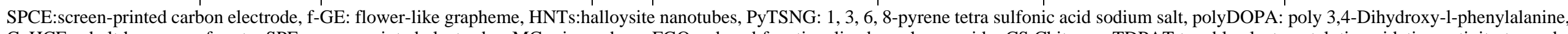

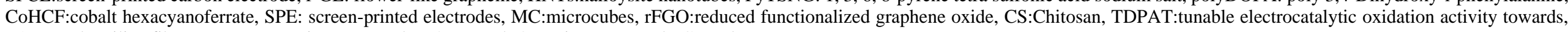
PANI: polyaniline fibrous nanocomposite supported, MOF:Metal-Organic Framework, C: cycle 
3.4.3. $\mathrm{MnO}$ nanoparticle/Graphene-based nanocomposite.

Among numerous metal oxides, manganese dioxide has achieved much attention for electrode designing because of its low price, high electrocatalytic properties, easy access, and non-toxicity in comparison to $\mathrm{Co}$ and $\mathrm{Ni}[68,69]$ Jaiswal et al., used modified $\mathrm{MnO}_{2}$ which was decorated with GO nanocomposite, and screen-printed electrodes for nitrite detection in tap and packaged water. Amperometric results showed a detection range of $0.1 \mathrm{mM}-1000 \mathrm{mM}$ for nitrite, with LOD of $0.09 \mu \mathrm{M}$. No significant decrease in response was observed after 20 cycles [70] Muthumariappan et al. used manganese oxide and graphene oxide nanosheets in electrode designing for detection of nitrite in beef and drinking water, and the electrochemical results were promising. The detection range was $0.1-420 ; 490-1318 \mu \mathrm{M}$, LOD was 0.02 , and the oxidation response remained $97.8 \%$ after four weeks [71].

\subsection{4. $\mathrm{ZnO}$ nanoparticle/Graphene-based nanocomposite.}

Recently nanostructured zinc oxide has gained attention due to its great optical and electrical properties. On the other hand, the compilation of $\mathrm{ZnO}$ nanostructures into graphene provides new electrical, optical, and catalytic properties [72, 73]. Pandikumar et al. modified glassy carbon electrode with reduced graphene oxide and flower-like $\mathrm{ZnO}$, the results were equal to the detection range of $10-5000$, LOD of $33 \mu \mathrm{M}$ and excellent stability [74]. Table 3 shows the stability, sensitivity, and limit of detecting electrodes modified with metal/graphene nanoparticles to detect nitrate and nitrite in the a food sample.

\section{Conclusions and Future Perspectives}

The electrochemical sensors are inexpensive and easy to be miniaturized, which are why their vast usage in food processing, distribution, and storage, particularly in areas and countries that are economically underdeveloped. In recent years, due to graphene and metal nanoparticles' exclusive physical and chemical properties, they have been used to manufacture electrochemical sensors. In this article, we mainly focused on electrodes modified by graphene, metal nanoparticles, and composites. We compared them in terms of detection range, detection limit, sensitivity, and stability. The results showed that the application of metal/graphene nanocomposite in electrode modification could be a promising tool for nitrate/nitrite detection in foods. It can be a good alternative to the present methods.

\section{Funding}

This research received no external funding.

\section{Acknowledgments}

The present study was supported by the Vice-Chancellor of Research of Tabriz University of Medical Sciences, Iran. This article was written based on data obtained from Akbari A's M.Sc. thesis (grant number: 62022).

\section{Conflicts of Interest}

The authors declare no conflict of interest. 


\section{References}

1. Bahadoran, Z.; Ghasemi, A.; Mirmiran, P.; Mehrabi, Y.; Azizi, F.; Hadaegh, F. Estimation and validation of dietary nitrate and nitrite intake in Iranian population. Iran. J. Public Health 2019, 48, 162-170.

2. Hakeem, K.R.; Sabir, M.; Ozturk, M.; Akhtar, M.S.; Ibrahim, F.H.; Ashraf, M.; Ahmad, M.S.A. Nitrate and nitrogen oxides: sources, health effects and their remediation. Rev Environ Contam Toxicol 2016, 242, 183-217, https://doi.org/10.1007/978-3-319-51243-3_15.

3. Lundberg, J.O.; Carlström, M.; Weitzberg, E. Metabolic effects of dietary nitrate in health and disease. Cell Metab 2018, 28, 9-22, https://doi.org/10.1016/j.cmet.2018.06.007.

4. Ward, M.H.; Jones, R.R.; Brender, J.D.; De Kok, T.M.; Weyer, P.J.; Nolan, B.T.; Villanueva, C.M.; Van Breda,S.G. Drinking water nitrate and human health: an updated review. Int. J. Environ. Res. Public Health 2018, 15, https://doi.org/10.3390/ijerph15071557.

5. He, L.; Wang, K. C.; Luo, X.; Zhang, S. Effective indirect enrichment and determination of nitrite ion in water and biological samples using ionic liquid-dispersive liquid-liquid microextraction combined with high-performance liquid chromatography. J. Chromatogr. A 2011, 1218, 3595-3600, https://doi.org/10.1016/j.chroma.2011.04.014.

6. Kazemzadeh, A.; Ensafi, A.A.; Simultaneous determination of nitrite and nitrate in various samples using flow-injection spectrophotometric detection. Microchem. J. 2001, 69, 61-68, https://doi.org/10.1016/S0026265X(01)00072-8.

7. Zhang, H.; Zhang, L.; Lu, C.; Zhao, L.; Zheng, Z. CdTe nanocrystals-enhanced chemiluminescence from peroxynitrous acid-carbonate and its application to the direct determination of nitrite. SAA 2012, 85, 217222, https://doi.org/10.1016/j.saa.2011.09.063.

8. Merusi, C.; Corradini,C.; Cavazza, A.; Borromei,C.; Salvadeo, P. Determination of nitrates, nitrites and oxalates in food products by capillary electrophoresis with $\mathrm{pH}$-dependent electroosmotic flow reversal. Food Chem 2010, 120, 615-620, https://doi.org/10.1016/j.foodchem.2009.10.035.

9. Shivakumar, M.; Nagashree, K.; Manjappa,S.; Dharmaprakash, M. Electrochemical Detection of Nitrite Using Glassy Carbon Electrode Modified with Silver Nanospheres (AgNS) Obtained by Green Synthesis Using Pre-hydrolysed Liquor. Electroanalysis 2017, 29,1434-1442,https://doi.org/10.1002/elan.201600775.

10. Bahadır, E.; Sezgintürk, B. and M.K. Applications of graphene in electrochemical sensing and biosensing. Trends Analyt Chem 2016, 76, 1-14, https://doi.org/10.1016/j.trac.2015.07.008.

11. Solís-Fernández, P.; Bissett, M.; Ago, H. Synthesis, structure and applications of graphene-based 2D heterostructures. Chem. Soc. Rev 2017, 46, 4572-4613, https://doi.org/10.1039/C7CS00160F.

12. Huang, S.; Lu, S.; Huang, C.; Sheng, J.; Su,W.; Zhang, L.; Xiao, Q. Sensitive and selective stripping voltammetric determination of copper (II) using a glassy carbon electrode modified with amino-reduced graphene oxide and $\beta$-cyclodextrin. Microchim Acta 2015, 182, 2529-2539, https://doi.org/10.1007/s00604015-1627-0.

13. Liu, Q.; Shi, J.; Jiang, G. Application of graphene in analytical sample preparation. Trac-Trend Anal Chem 2012, 37, 1-11, https://doi.org/10.1016/j.trac.2012.03.011.

14. Mehmeti, E.; Stanković, D.M.; Hajrizi, A.; Kalcher, K. The use of graphene nanoribbons as efficient electrochemical sensing material for nitrite determination. Talanta 2016, 159, 34-39, https://doi.org/10.1016/j.talanta.2016.05.079.

15. Mani, V.; Periasamy, A.P.; Chen, S. M. Highly selective amperometric nitrite sensor based on chemically reduced graphene oxide modified electrode. Electrochem commun 2012, 17, 75-78, https://doi.org/10.1016/j.elecom.2012.02.009.

16. Zhang, J.; Zhang, Y.; Zhou, J.; Wang, L. Construction of a highly sensitive non-enzymatic nitrite sensor using electrochemically reduced holey graphene. Anal. Chim. Acta 2018, 1043, 28-34, https://doi.org/10.1016/j.aca.2018.08.045.

17. Chen, D.; Jiang, J.; Du, X. Electrocatalytic oxidation of nitrite using metal-free nitrogen-doped reduced graphene oxide nanosheets for sensitive detection. Talanta 2016, 155, 329-335, https://doi.org/10.1016/j.talanta.2016.05.003.

18. Palanisamy, S.; Karuppiah, C.; Chen, S.M.; Periakaruppan, P. Highly sensitive and selective amperometric nitrite sensor based on electrochemically activated graphite modified screen printed carbon electrode. J. Electroanal. Chem 2014, 727, 34-38, https://doi.org/10.1016/j.jelechem.2014.05.025.

19. Losada, J.; Armada, M.P.G.; Garcia, E.; Casado, C.M.; Alonso, B. Electrochemical preparation of gold nanoparticles on ferrocenyl-dendrimer film modified electrodes and their application for the electrocatalytic oxidation and amperometric detection of nitrite. J. Electroanal. Chem 2017, 788, 14-22, https://doi.org/10.1016/j.jelechem.2017.01.066.

20. Chen, H.; Yang, T.; Liu, F.; Li, W. Electrodeposition of gold nanoparticles on Cu-based metal-organic framework for the electrochemical detection of nitrite. Sens. Actuators B Chem 2019, 286, 401-407, https://doi.org/10.1016/j.snb.2018.10.036.

21. Wan, Y.; Zheng,Y.F.; Yin, H.Y.; Song, X.C. Au nanoparticle modified carbon paper electrode for an electrocatalytic oxidation nitrite sensor. New J Chem 2016, 40, 3635-3641, https://doi.org/10.1039/C5NJ02941D. 
22. Wang, P.; Mai, Z.; Dai, Z.; Li,Y.; Zou, X. Construction of Au nanoparticles on choline chloride modified glassy carbon electrode for sensitive detection of nitrite. Biosens. Bioelectron 2009, 24, 3242-3247, https://doi.org/10.1016/j.bios.2009.04.006.

23. Yu, C.; Guo, J.; Gu, H. Electrocatalytical oxidation of nitrite and its determination based on Au@ Fe3O4 nanoparticles. Electroynalysis (N.Y.N.Y.) 2010, 22, 1005-1011, https://doi.org/10.1002/elan.200900465.

24. Huang, S.S.; Liu, L.; Mei, L.P.; Zhou, J.Y.; Guo, F.Y.; Wang, A.J.; Feng, J.J. Electrochemical sensor for nitrite using a glassy carbon electrode modified with gold-copper nanochain networks. Microchim Acta 2016, 183, 791-797, https://doi.org/10.1007/s00604-015-1717-z.

25. Liu, T.S.; Kang, T.F.; Lu, L.P.; Zhang,Y.; Cheng, S.Y. Au-Fe (III) nanoparticle modified glassy carbon electrode for electrochemical nitrite sensor. J. Electroanal. Chem 2009, 632, 197-200, https://doi.org/10.1016/j.jelechem.2009.04.023.

26. Zeng, Y.; Zhu, Z.; Du, D.; Lin, Y. Nanomaterial-based electrochemical biosensors for food safety. J. Electroanal. Chem 2016, 781, 147-154, https://doi.org/10.1016/j.jelechem.2016.10.030.

27. Parsaei, M.; Asadi, Z.; Khodadoust, S. A sensitive electrochemical sensor for rapid and selective determination of nitrite ion in water samples using modified carbon paste electrode with a newly synthesized cobalt (II)-Schiff base complex and magnetite nanospheres. Sens. Actuators B Chem 2015, 220, 1131-1138, https://doi.org/10.1016/j.snb.2015.06.096.

28. Dhanya, S.; Saumya,V.; Rao, T.P. Synthesis of silver nanoclusters, characterization and application to trace level sensing of nitrate in aqueous media. Electrochim. Acta 2013, 102, 299-305, https://doi.org/10.1016/j.electacta.2013.04.017.

29. Guadagnini, L.; Tonelli, D. Carbon electrodes unmodified and decorated with silver nanoparticles for the determination of nitrite, nitrate and iodate. Sens. Actuators B Chem 2013, 188, 806-814, https://doi.org/10.1016/j.snb.2013.07.077.

30. Hu, J.; Sun, J.; Bian, C.; Tong, J.; Shanhong, X. 3D Dendritic Nanostructure of Silver-Array: Preparation, Growth Mechanism and Application in Nitrate Sensor. Electroanalysis 2013, 25, 546-556, https://doi.org/10.1002/elan.201200465

31. Rudbaraki, A.; Khalilzadeh, M.A. Analysis of nitrite using a voltammetric sensors employing NiO nanoparticle modified carbon paste electrode. Anal. Bioanal. Electrochem 2016, 8.

32. Xia, C.; Xiaolan, C.; Ning, W.; Lin,G. Hierarchical CuO nanochains: synthesis and their electrocatalytic determination of nitrite. Anal. Chim. Acta 2011, 691, 43-47, https://doi.org/10.1016/j.aca.2011.02.037.

33. Zhang, M.L.; Cao, Z.; He, J.L.; Xue, L.; Zhou, Y.; Long, S.; Deng, T.; Zhang, L. A simple gold plate electrode modified with Gd-doped $\mathrm{TiO} 2$ nanoparticles used for determination of trace nitrite in cured food. Food Addit Contam A 2012, 29, 1938-1946, https://doi.org/10.1080/19440049.2012.715762.

34. Liu, Y.; Zhou,J.; Gong, J.; Wu,W.P.; Bao,N.; Pan, Z.Q.; Gu, H.Y. The investigation of electrochemical properties for Fe3O4@Pt nanocomposites and an enhancement sensing for nitrite. Electrochim. Acta 2013, 111, 876-887, https://doi.org/10.1016/j.electacta.2013.08.077.

35. He, Q.; Gan,T.; Zheng, D.; Hu, S. Direct electrochemistry and electrocatalysis of nitrite based on nanoalumina-modified electrode. J Solid State Electrochem 2010, 14, 1057-1064, https://doi.org/10.1007/s10008-009-0915-1.

36. Lu, L.; Wang, S.; Kang,T.; Xu, W. Synergetic effect of Pd-Fe nanoclusters: electrocatalysis of nitrite oxidation. Microchim Acta 2008, 162, 81-85, https://doi.org/10.1007/s00604-007-0893-X.

37. Li, Y.; Wang, H.; Liu, X.; Guo, L.; Ji, X.; Wang, L.; Tian, D.; Yang, X. Nonenzymatic nitrite sensor based on a titanium dioxide nanoparticles/ionic liquid composite electrode. J. Electroanal. Chem 2014, 719, 3540, https://doi.org/10.1016/j.jelechem.2014.02.006.

38. Wang, J.; Xu, G.; Wang,W.; Xu, S.; Luo, X. Nitrite oxidation with copper-cobalt nanoparticles on carbon nanotubes doped conducting polymer PEDOT composite. Chem. Asian J 2015, 10, 1892-1897, https://doi.org/10.1002/asia.201500579.

39. Lu, T.; Zhang,Y.; Pan, H. L.; Li,Y.; Sun, Z. Electrochemical behaviors of graphene-ZnO and graphene$\mathrm{SnO} 2$ composite films for supercapacitors. Electrochim. Acta 2010, 55, 4170-4173, https://doi.org/10.1016/j.electacta.2010.02.095.

40. Zhang, M.; Cheng, F.; Gan, F. Electrochemical nitrite nanosensor based on Au nanoparticles/graphene nanocomposites. Int. J. Eelectrochem. Sci 2015, 10.

41. Jian, J.M.; Fu, L.; Ji, J.; Lin, L.; Guo, X.; Ren, T L. Electrochemically reduced graphene oxide/gold nanoparticles composite modified screen-printed carbon electrode for effective electrocatalytic analysis of nitrite in foods. Sens. Actuators B Chem 2018, 262, 125-136, https://doi.org/10.1016/j.snb.2018.01.164.

42. Zou, C.E.; Yang, B.; Bin, D.; Wang, J.; Li, S.; Yang, P.; Wang, C.; Shiraishi,Y.; Du,Y. Electrochemical synthesis of gold nanoparticles decorated flower-like graphene for high sensitivity detection of nitrite. $J$. Colloid Interface Sci 2017, 488, 135-141, https://doi.org/10.1016/j.jcis.2016.10.088.

43. He, B.S.; Yan, D.D. One-pot preparation of wavy graphene/Au composites and their application for highly sensitive detection of nitrite. Anal. Methods 2018, 10, 3654-3659, https://doi.org/10.1039/C8AY01215F.

44. Zhang, S.; Sheng, Q.; Zheng, J. Synthesis of Au nanoparticles dispersed on halloysite nanotubes-reduced graphene oxide nanosheets and their application for electrochemical sensing of nitrites. New J Chem 2016, 40, 9672-9678, https://doi.org/10.1039/C6NJ02103D. 
45. Li, Z.; An, Z.; Guo,Y.; Zhang, K.; Chen, X.; Zhang, D.; Xue, Z.; Zhou, X.; Lu, X. Au-Pt bimetallic nanoparticles supported on functionalized nitrogen-doped graphene for sensitive detection of nitrite. Talanta 2016, 161, 713-720, https://doi.org/10.1016/j.talanta.2016.09.033.

46. Li, S.S.; Hu,Y.Y.; Wang, A.J.; Weng, X.; Chen, J.R.; Feng, J.J. Simple synthesis of worm-like Au-Pd nanostructures supported on reduced graphene oxide for highly sensitive detection of nitrite. Sens. Actuators B Chem 2015, 208 , 468-474, https://doi.org/10.1016/j.snb.2014.11.056.

47. Bai, W.; Sheng,Q.; Zheng, J. Morphology controlled synthesis of platinum nanoparticles performed on the surface of graphene oxide using a gas-liquid interfacial reaction and its application for high-performance electrochemical sensing. Analyst 2016, 141, 4349-4358, https://doi.org/10.1039/C6AN00632A.

48. Yang, B.; Bin, D.; Wang, H.; Zhu, M.; Yang, P.; Du, Y. High quality Pt-graphene nanocomposites for efficient electrocatalytic nitrite sensing. Colloids Surf. A Physicochem. Eng. Asp 2015, 481, 43-50, https://doi.org/10.1016/j.colsurfa.2015.04.027.

49. Vijayaraj, K.; Jin, S.H.; Park, D.S. A sensitive and selective nitrite detection in water using $\begin{array}{lllll}\text { graphene/platinum } & \text { nanocomposite. } & \text { Electroanalysis } & \mathbf{2 0 1 7}, & \text { 29, }\end{array}$ https://doi.org/10.1002/elan.201600133.

50. Hameed, R.A.; Medany, S.S. Construction of core-shell structured nickel@ platinum nanoparticles on graphene sheets for electrochemical determination of nitrite in drinking water samples. Microchem J 2019, 145, 354-366, https://doi.org/10.1016/j.microc.2018.10.045.

51. Hameed, R.A.; Medany, S.S. Evaluation of core-shell structured cobalt@ platinum nanoparticles-decorated graphene for nitrite sensing. Synth. Met 2019, 247, 67-80, https://doi.org/10.1016/j.synthmet.2018.11.011.

52. Hameed, R.A.; Medany, S.S. Sensitive nitrite detection at core-shell structured Cu@ Pt nanoparticles supported on graphene. Appl. Surf. Sci 2018, 458, 252-263, https://doi.org/10.1016/j.apsusc.2018.07.079.

53. Marković, B.M.; Maksin, D.D.; Mojović, Z.D.; Vuković, Z.M.; Nastasović, A.B.; Jovanović, D.M. Electrochemical behavior of palladium modified amino-functionalized macroporous copolymer. $J$. Electroanal. Chem 2017, 786, 94-101, https://doi.org/10.1016/j.jelechem.2017.01.018.

54. Fu, L.; Thompson, S.L.; Yu, A. Development of a novel nitrite electrochemical sensor by stepwise in situ formation of palladium and reduced graphene oxide nanocomposites. RSC Adv 2015, 5, 40111-40116, https://doi.org/10.1039/C5RA02661J.

55. Zhao, Z.; Xia, Z.; Liu, C.; Huang, H.; Ye, W. Green synthesis of Pd/Fe3O4 composite based on polyDOPA functionalized reduced graphene oxide for electrochemical detection of nitrite in cured food. Electrochim. Acta 2017, 256, 146-154, https://doi.org/10.1016/j.electacta.2017.09.185.

56. Zhang, M.; Liu, J.; Nie, F.; Zheng, J. Facile synthesis of TiO 2-functionalized graphene nanosheet-supported Ag catalyst and its electrochemical oxidation of nitrite. J. Iran. Chem. Soc 2015, 12, 1535-1542, https://doi.org/10.1007/s13738-015-0625-9.

57. Ikhsan, N.I.; Rameshkumar, P.; Pandikumar, A.; Shahid, M.M.; Huang, N.M.; Kumar, S.V.; Lim, H.N. Facile synthesis of graphene oxide-silver nanocomposite and its modified electrode for enhanced electrochemical detection of nitrite ions. Talanta 2015, 144, 908-914, https://doi.org/10.1016/j.talanta.2015.07.050.

58. Ahmad, R.; Mahmoudi, T.; Ahn, M.S.; Yoo, J.Y.; Hahn, Y.B. Fabrication of sensitive non-enzymatic nitrite sensor using silver-reduced graphene oxide nanocomposite. J. Colloid Interface Sci 2018, 516, 67-75, https://doi.org/10.1016/j.jcis.2018.01.052.

59. Wang, H.; Wang, C.; Yang, B.; Zhai, C.; Bin, D.; Zhang, K.; Yang, P.; Du,Y. A facile fabrication of copper particle-decorated novel graphene flower composites for enhanced detecting of nitrite. Analyst 2015, 140, 1291-1297, https://doi.org/10.1039/C4AN01924E.

60. Majidi, M.R.; Ghaderi, S. Hydrogen bubble dynamic template fabrication of nanoporous Cu film supported by graphene nanaosheets: a highly sensitive sensor for detection of nitrite. Talanta 2017, 175, 21-29, https://doi.org/10.1016/j.talanta.2017.07.020.

61. Li, G.; Xia, Y.; Tian,Y.; Wu, Y.; Liu, J.; He, Q.; Chen, D. Recent Developments on Graphene-Based Electrochemical Sensors toward Nitrite. J. Electrochem. Soc 2019, 166, https://doi.org/10.1149/2.0171912jes.

62. Chen, A.; Xu, L.; Zhang, X.; Yang, Z.; Yang, S. Improving surface adsorption via shape control of hematite a-Fe2O3 nanoparticles for sensitive dopamine sensors. ACS Appl. Mater. Interfaces 2016, 8, 33765-33774, https://doi.org/10.1021/acsami.6b11088.

63. Radhakrishnan, S.; Krishnamoorthy, K.; Sekar, C.; Wilson, J.; Kim, S.J. A highly sensitive electrochemical sensor for nitrite detection based on $\mathrm{Fe} 2 \mathrm{O} 3$ nanoparticles decorated reduced graphene oxide nanosheets. Appl. Catal. B 2014, 148, 22-28, https://doi.org/10.1016/j.apcatb.2013.10.044.

64. Nam, K.T.; Kim, D.W.; Yoo, P.J.; Chiang, C.Y.; Meethong, N.P.; Hammond, T.; Chiang, Y.M.; Belcher, A.M. Virus-enabled synthesis and assembly of nanowires for lithium ion battery electrodes. Science 2006, 312, 885-888, https://doi.org/10.1126/science.1122716.

65. Lu, Y.; Wang,Y.; Zou,Y.; Jiao, Z.; Zhao, B.; He, Y.; Wu, M. Macroporous Co3O4 platelets with excellent rate capability as anodes for lithium ion batteries. Electrochem. commun 2010, 12, 101-105, https://doi.org/10.1016/j.elecom.2009.10.046. 
66. Stanković, D.M.; Mehmeti, E.; Zavašnik, J.; Kalcher, K. Determination of nitrite in tap water: A comparative study between cerium, titanium and selenium dioxide doped reduced graphene oxide modified glassy carbon electrodes. Sens. Actuators B Chem 2016, 236, 311-317, https://doi.org/10.1016/j.snb.2016.06.018.

67. Luo, X.; Pan, J.; Pan, K.; Yu, Y.; Zhong, A.; Wei, S.; Li, J.; Shi, J.; Li, X. An electrochemical sensor for hydrazine and nitrite based on graphene-cobalt hexacyanoferrate nanocomposite: Toward environment and food detection. J. Electroanal. Chem 2015,745, 80-87, https://doi.org/10.1016/j.jelechem.2015.03.017.

68. Prasad, H.; Prasat, R.; Hashim, U. A review on the label free nanowire based biosensor. J. Appl. Sci. Res 2012, 8, 4759-4769.

69. Beyene, N.W.; Kotzian, P.; Schachl, K.; Alemu, H.; Turkušić, E.; Čopra, A.; Moderegger, H.; Švancara, I.; Vytřas, K.; Kalcher, K. (Bio) sensors based on manganese dioxide-modified carbon substrates: retrospections, further improvements and applications. Talanta 2004, 64, 1151-1159, https://doi.org/10.1016/j.talanta.2004.03.068.

70. Jaiswal, N.; Tiwari, I.; Foster, C.W.; Banks, C.E. Highly sensitive amperometric sensing of nitrite utilizing bulk-modified $\mathrm{MnO} 2$ decorated Graphene oxide nanocomposite screen-printed electrodes. Electrochim. Acta 2017, 227, 255-266, https://doi.org/10.1016/j.electacta.2017.01.007.

71. Muthumariappan, A.; Govindasamy, M.; Chen, S.M.; Sakthivel, K.; Mani, V. Screen-printed electrode modified with a composite prepared from graphene oxide nanosheets and $\mathrm{Mn} 3 \mathrm{O} 4$ microcubes for ultrasensitive determination of nitrite. Microchim Acta 2017, 184, 3625-3634, https://doi.org/10.1007/s00604-017-2379-9.

72. Lee, J.H.; Ko, K.H.; Park, B.O. Electrical and optical properties of ZnO transparent conducting films by the sol-gel method. J. Cryst. Growth 2003, 247, 119-125, https://doi.org/10.1016/S0022-0248(02)01907-3.

73. Zhang, Q.; Xie, C.; Zhang, S.; Wang, A.; Zhu, B.; Wang, L.; Yang, Z. Identification and pattern recognition analysis of Chinese liquors by doped nano ZnO gas sensor array. Sens. Actuators B Chem 2005, 110, 370376, https://doi.org/10.1016/j.snb.2005.02.017.

74. Pandikumar, A.; Yusoff, N.; Huang, N.M.; Lim, H.N. Electrochemical sensing of nitrite using a glassy carbon electrode modified with reduced functionalized graphene oxide decorated with flower-like zinc oxide. Microchim Acta 2015, 182, 1113-1122, https://doi.org/10.1007/s00604-014-1436-x.

75. Ma, C.; Qian,Y.; Zhang, S.; Song, H.; Gao, J.; Wang, S.; Liu, M.; Xie, K.; Zhang, X. Temperature-controlled ethanolamine and Ag-nanoparticle dual-functionalization of graphene oxide for enhanced electrochemical nitrite determination. Sens. Actuators $B$ Chem 2018, 274, 441-450, https://doi.org/10.1016/j.snb.2018.08.012.

76. Mo, R.; Wang, X.; Yuan, Q.; Yan, X.; Su,T.; Feng,Y.; Lv, L.; Zhou, C.; Hong, P.; Sun, S. Electrochemical determination of nitrite by au Nanoparticle/Graphene-Chitosan modified electrode. Sensors 2018, 18, https://doi.org/10.3390/s18071986.

77. Rostami, M.; Abdi, G.; Kazemi, S.H.; Alizadeh, A. Nanocomposite of magnetic nanoparticles/graphene oxide decorated with acetic acid moieties on glassy carbon electrode: A facile method to detect nitrite concentration. J. Electroanal. Chem 2019, 847, https://doi.org/10.1016/j.jelechem.2019.113239.

78. He, B.; Yan, D. Au/ERGO nanoparticles supported on Cu-based metal-organic framework as a novel sensor for sensitive determination of nitrite. Food Control 2019, 103, 70-77, https://doi.org/10.1016/j.foodcont.2019.04.001.

79. Yue, X.; Luo, X.; Zhou, Z.; Wu, Y.; Bai, Y. pH-regulated synthesis of CuO x/ERGO nanohybrids with tunable electrocatalytic oxidation activity towards nitrite sensing. New J Chem 2019, 43, 4947-4958, https://doi.org/10.1039/C9NJ00474B.

80. Li, X.; Hou, S.; Xie, C.; Fan, G. Graphene-TiO2 Nanocomposite-Modified Screen-Printed electrode for sensitive nitrite determination in hot spring water. Int. J. Electrochem. Sci 2018, 13, 315-323, https://doi.org/10.20964/2018.01.38.

81. Wang, Y.; Cao,W.; Yin, C.; Zhuang, Q.; Ni, Y. Nonenzymatic amperometric sensor for nitrite detection based on a nanocomposite consisting of nickel hydroxide and reduced graphene oxide. Electroanalysis 2018, 30, 2916-2924, https://doi.org/10.1002/elan.201800627.

82. Sahoo, S.; Sahoo, P.; Sharma, A.; Satpati, A. Interfacial polymerized RGO/MnFe2O4/polyaniline fibrous nanocomposite supported glassy carbon electrode for selective and ultrasensitive detection of nitrite. Sens. Actuators B Chem 2020, 309,. https://doi.org/10.1016/j.snb.2020.127763.

83. Rashed, M.A.; Faisal, M.; Harraz, F.A.; Jalalah, M.; Alsaiari, M.; Al-Assiri, M. rGO/ZnO/Nafion nanocomposite as highly sensitive and selective amperometric sensor for detecting nitrite ions (NO2-). J Taiwan Inst Chem Eng 2020, 112, 345-356, https://doi.org/10.1016/j.jtice.2020.05.015.

84. Arul, P.; Gowthaman, N.; John, S.A.; Lim, H.N. Ultrasonic Assisted Synthesis of Size-Controlled Cu-MetalOrganic Framework Decorated Graphene Oxide Composite: Sustainable Electrocatalyst for the Trace-Level Determination of Nitrite in Environmental Water Samples. ACS Omega 2020, 5, 14242-14253, https://doi.org/10.1021/acsomega.9b03829. 